\title{
Antiretroviral therapy for adults infected with HIV: Guidelines for health care professionals from the Quebec HIV care committee
}

\author{
Danielle Rouleau MD MSc FRCPC ${ }^{1}$, Claude Fortin MD FRCPC ${ }^{1}$, Benoît Trottier MD ${ }^{1,2}$, Richard Lalonde MD FRCPC ${ }^{3}$, \\ Normand Lapointe MD MSc FRCPC ${ }^{4}$, Pierre Côté MD ${ }^{1,5,6}$, Jean-Pierre Routy $\mathrm{MD}^{3}$, Marie-France Matte ${ }^{7}$, \\ Irina Tsarevsky ${ }^{7}$, Jean-Guy Baril $M D^{1,5,7}$; for the Comité consultatif sur la prise en charge \\ clinique des personnes vivant avec le VIH
}

D Rouleau, C Fortin, B Trottier; for the Comité consultatif sur la prise en charge clinique des personnes vivant avec le VIH. Antiretroviral therapy for adults infected with HIV: Guidelines for health care professionals from the Quebec HIV care committee. Can J Infect Dis Med Microbiol 2011;22(2):52-60.

The appropriate use of antiretrovirals reduces morbidity and mortality caused by HIV infection. The present article provides health care professionals with a practical guide for the use of antiretrovirals. Therapy should be initiated based predominantly on clinical presentation and CD4 count, and should consist of three active drugs or at least two active drugs when this is not possible, as in cases of some treatmentexperienced patients. This is the most effective way to achieve longterm suppression of viral replication. Selection of individual drugs in the regimen should consider the weight of the evidence supporting these choices, as well as their tolerability profiles and ease of use, the patients' comorbidities and treatment history. Treatment interruption is not recommended, either in aviremic patients or in those who have experienced virological failure. Instead, the therapeutic regimen should be adjusted to minimize side effects, promote adherence and suppress viral replication.

\section{L'antirétrovirothérapie pour les adultes infectés par le VIH : Lignes directrices pour les professionnels de la santé du comité québécois des soins du VIH}

Key Words: Antiretrovirals; HAART; HIV; Practical guide

A ntiretroviral therapy decreases mortality rates and improves quality of life by suppressing HIV replication. The availability of new generations of antiretrovirals opens additional therapeutic options for many patients, but also makes the task of optimizing treatment more complex. The present article provides health care professionals with a practical guide to antiretroviral therapy for HIV-infected adults. These recommendations also serve to support academic teaching and continuous medical education, as well as giving clinicians a voice in governmental decision-making processes.

The present guide was developed by a writing committee and approved by the Comité consultatif sur la prise en charge clinique des personnes vivant avec le VIH (Advisory Committee on the Clinical Management of Persons Living with HIV) - a Quebec-based panel of experts mandated by the Ministère de la Santé et des Services sociaux (Ministry of Health and Social Services) to establish clinical guidelines for the management and treatment of persons living with HIV. These recommendations were achieved by consensus and were based
L'utilisation pertinente d'antirétroviraux réduit la morbidité et la mortalité attribuables à l'infection par le VIH. Le présent article fournit aux professionnels de la santé un guide pratique sur l'usage des antirétroviraux. Pour amorcer la thérapie, il faut se fier en grande partie à la présentation clinique et à la numération des lymphocytes CD4. Cette thérapie doit se composer de trois médicaments actifs ou, si c'est impossible, d'au moins deux médicaments actifs, comme c'est le cas chez certains patients déjà traités. C'est le moyen le plus efficace d'obtenir une suppression à long terme de la réplication virale. La sélection des médicaments de cette posologie doit tenir compte du poids de la preuve en appui à ces trois choix, de même que des profils de tolérabilité et de la facilité d'utilisation, des comorbidités du patient et de ses antécédents thérapeutiques. L'interruption du traitement n'est pas recommandée, que ce soit chez les patients avirémiques ou chez ceux qui ont subi un échec virologique. Il faut plutôt rajuster la posologie pour réduire les effets secondaires au minimum, promouvoir l'adhésion au traitement et supprimer la réplication virale.

\footnotetext{
${ }^{1}$ Unité hospitalière de recherche, d'enseignement et de soins sur le sida (UHRESS), Centre hospitalier de l'Université de Montréal;

${ }^{2}$ Clinique médicale l'Actuel; ${ }^{3}$ UHRESS, McGill University Health Centre; ${ }^{4}$ UHRESS, Centre hospitalier universitaire Sainte-Justine,

Université de Montréal; ${ }^{5}$ Clinique médicale du Quartier Latin; ${ }^{6}$ Programme national de mentorat sur le VIH-sida; ${ }^{7}$ Service de lutte contre les infections transmissibles sexuellement par le sang, Ministère de la Santé et des Services sociaux, Montréal, Québec

Correspondence: Dr Danielle Rouleau, Département de microbiologie, CHUM - Campus Notre-Dame, 1560, rue Sherbrooke Est, Montréal,

Québec H2L 4M1. Telephone 514-890-8000 ext 26265, fax 514-412-7512, e-mail danielle.rouleau.chum@ssss.gouv.qc.ca
} 
TABLE 1

Explanation of recommendation grading system

\begin{tabular}{ll}
\hline Strength of recommendation & \\
\hline B & $\begin{array}{c}\text { The therapy is strongly recommended } \\
\text { The therapy is moderately recommended } \\
\text { Implementation of the recommendation is } \\
\text { optional } \\
\text { The therapy is generally not recommended }\end{array}$ \\
D & The therapy is contraindicated \\
E & $\begin{array}{l}\text { At least one randomized controlled clinical } \\
\text { trial }\end{array}$ \\
I & Noncontrolled clinical studies, \\
II & case studies or cohort studies \\
III & Expert opinion
\end{tabular}

Adapted from reference 1

as on the Programme national de mentorat sur le VIH/Sida (National HIV/AIDS Mentorship Program) website (www.pnmvs.org). The source article includes an extensive review of the studies on which the following recommendations are based, as well as a table summarizing the relevant drug-drug interactions.

\section{THE PRINCIPLES OF ANTIRETROVIRAL THERAPY}

The goals of antiretroviral therapy in HIV infection are multifold and often complementary. In addition to maintaining the health of persons living with HIV and reducing morbidity and mortality due to HIV infection, they include the following: long-term suppression of viral replication; improvement in immune function and enhancement of the quality of life in HIV-infected persons; prevention of viral resistance to medications; minimizing medication-related side effects; preserving future therapeutic options and preventing mother-to-child transmission of HIV. All persons infected with HIV, even those receiving antiretroviral therapy who have a plasma viral load below the threshold for detection, should be considered to be potentially infectious and should receive appropriate advice on the risks of HIV transmission. This position is different than that of the Commission fédérale suisse pour les problèmes liés au sida (Swiss Federal Commission for HIV/AIDS), which states that a seropositive person not harbouring any other sexually transmitted infection and undergoing antiretroviral treatment with completely suppressed viremia does not transmit HIV through sexual contact (2). The Swiss position is not endorsed by the international medical community because the currently available evidence does not prove that effective antiretroviral therapy prevents all transmission of HIV (3). Although no well-documented cases of transmission in the presence of a viral load of less than 50 copies/mL have been reported $(4,5)$, cases of viral replication in sperm and female genital secretions have been documented in the absence of viral replication in plasma (6-8). Thus, insofar as low-level viral replication can occur even when the plasma viral load is below the threshold for detection, a theoretical risk of HIV transmission exists even in patients with an undetectable viral load (9) and this risk should be discussed with serodiscordant couples.

Long-term suppression of HIV replication is achieved through a combination of fully active antiretroviral drugs, determined based on the results of resistance testing and the patient's history of drug exposure.

\section{INITIATION OF ANTIRETROVIRAL THERAPY}

Antiretroviral therapy should be initiated for AIDS patients and individuals presenting with serious clinical symptoms related to HIV (such as fever, weight loss, diarrhea, severe Candida infection, etc), independent of CD4 count and viral load (AI) (Table 2).

In asymptomatic patients, the risk of progression to AIDS or recurrence of an opportunistic infection increases with the presence of one
TABLE 2

Initiation of antiretroviral therapy based on clinical presentation and CD4 count

\begin{tabular}{|c|c|c|}
\hline Clinical presentation & $\begin{array}{l}\text { CD4 count } \\
\text { (cells/ } \mu \mathrm{L})\end{array}$ & $\begin{array}{l}\text { Treatment recommendation } \\
\text { (strength of evidence) }\end{array}$ \\
\hline Symptomatic & All counts & Initiate therapy (AI) \\
\hline \multicolumn{3}{|l|}{ Opportunistic infection } \\
\hline \multicolumn{3}{|c|}{ AIDS-associated neoplasia } \\
\hline \multicolumn{3}{|c|}{ HIV-associated nephropathy } \\
\hline \multicolumn{3}{|l|}{ Pregnancy } \\
\hline HIV/HBV coinfection & All counts & $\begin{array}{l}\text { Initiate regimen including two } \\
\text { anti-HBV NRTIs (tenofovir } \\
\text { plus either lamivudine or } \\
\text { emtricitabine) when treatment } \\
\text { of hepatitis is required (AII) }\end{array}$ \\
\hline Asymptomatic & $<350$ & Initiate therapy (AII) \\
\hline Asymptomatic & $\geq 350$ & $\begin{array}{l}\text { Individualize decisions taking } \\
\text { into consideration viral load, } \\
\text { clinical context and } \\
\text { comorbidities* (CIII) }\end{array}$ \\
\hline
\end{tabular}

*Factors that must be taken into account include the patient's motivation, viral load, rate of decline of CD4 count and coinfection with the hepatitis C virus, because early antiretroviral treatment can delay progression to fibrosis. Antiretroviral therapy should be considered for patients with a CD4 count of greater than 350 cells/ $\mu \mathrm{L}$, if the CD4 count is declining rapidly (decrease of more than 100 cells/ $\mu \mathrm{L} /$ year) or if the HIV viral load is greater than 100,000 copies $/ \mathrm{mL}$ (CII). HBV Hepatitis B virus; NRTIs Nucleoside and nucleotide reverse transcriptase inhibitors

or more of the following factors: lower CD4 count, viral load of 100,000 copies/mL or greater, older than 50 years of age, injection drug use and previous diagnosis of AIDS (10-14).

Of these factors, CD4 count is paramount in establishing when to initiate treatment, although the viral load may predict the rapidity of progression (10-12). There is evidence from cohort studies $(12,15-17)$ that antiretroviral treatment is associated with survival benefits in asymptomatic patients with a CD4 count below 200 cells/ $\mu \mathrm{L}$. However, there are no data from controlled studies confirming the optimal time to initiate antiretroviral therapy in asymptomatic patients with a CD4 count above 200 cells/ $\mu$ L. Observational cohort studies (18-20) evaluating survival as a function of CD4 count at the start of treatment have shown that there is a significant advantage to beginning treatment near the 350 cells $/ \mu \mathrm{L}$ threshold. The benefits of initiating treatment above 350 cells $/ \mu \mathrm{L}$ are less certain, although cohort studies have demonstrated that such therapy is associated with more frequent normalization of CD4 count $(14,21)$, a decrease in mortality in one study (20) and a lower risk of conditions such as peripheral neuropathy, anemia and renal insufficiency (22) compared with starting treatment at a CD4 count of less than 350 cells/ $\mu \mathrm{L}$.

Treatment of asymptomatic HIV infection should be initiated when the CD4 count has been shown by repeated testing to have decreased to 350 cells $/ \mu \mathrm{L}$ (AII) (Table 2). For patients with CD4 counts of greater than 350 cells $/ \mu \mathrm{L}$, antiretroviral treatment should be considered if the CD4 count declines rapidly (at a rate greater than 100 cells $/ \mu \mathrm{L} /$ year) or if the plasma viral load is greater than 100,000 copies/mL (CII) $(23,24)$. Other factors to consider when deciding whether to initiate therapy include the patient's willingness to start treatment (12) and whether the patient is coinfected with the hepatitis $\mathrm{C}$ virus, because early antiretroviral treatment can delay progression to liver fibrosis in coinfected patients $(25,26)$. Other conditions, such as HIV-associated nephropathy, infection with hepatitis B virus (HBV) and pregnancy, may also influence the decision to initiate treatment (Table 2). For instance, pregnant women should be treated regardless of CD4 count to prevent maternofetal transmission of HIV (AI).

HIV-associated nephropathy, a condition observed more frequently in black people, is a cause of chronic kidney disease in persons living 
TABLE 3

Antiretroviral agents available in Canada

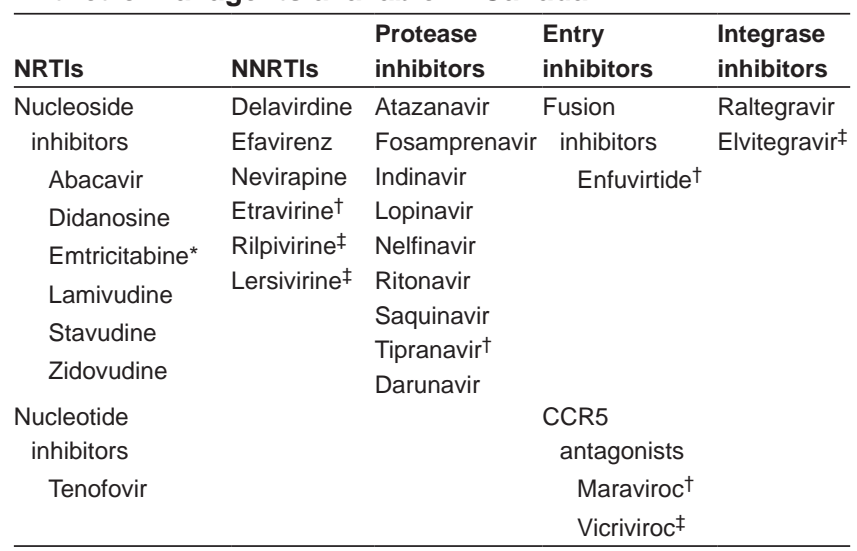

*Only available in coformulation with tenofovir (Truvada [Gilead Sciences, USA]); 'Only indicated in treatment-experienced patients in Canada; ${ }^{\ddagger}$ Medications in development currently being used in research in Canada - other medications currently in development may not be listed. NNRTIs Non-nucleoside reverse transcriptase inhibitors; NRTIs Nucleotide and nucleoside reverse transcriptase inhibitors

with HIV. The pathogenesis of this condition involves replication of HIV in kidney tissue. Antiretroviral therapy has been shown to preserve renal function and improve survival prognosis in these patients regardless of the degree of immunosuppression $(27,28)$. Treatment of HIV-associated nephropathy with antiretroviral therapy is thus recommended, regardless of CD4 count (AII).

When treatment of HBV infection is required in the context of HIV coinfection, initiating anti-HIV therapy that includes tenofovir with lamivudine or emtricitabine, which acts against both HIV and $\mathrm{HBV}$, is recommended (BIII). This recommendation aims to avoid exposing HIV to suboptimal nucleoside or nucleotide analogue monotherapy when treatment for HBV is required and CD4 counts have not decreased below the 350 cells $/ \mu \mathrm{L}$ threshold (29).

Finally, there is no conclusive evidence to suggest that the treatment of acute HIV infection should be based on different criteria than those used for chronic infection. However, treatment may be offered to persons presenting with recent HIV seroconversion (less than six months) in the context of a clinical trial, in consultation with an expert in this area (CIII) (30).

\section{SELECTION OF FIRST-LINE ANTIRETROVIRAL TREATMENT}

Antiretroviral agents available in Canada (Table 3), whether currently approved or available through compassionate access programs or research protocols, can be divided into six classes:

- Nucleoside and nucleotide reverse transcriptase inhibitors (NRTIs);

- Non-nucleoside reverse transcriptase inhibitors (NNRTIs);

- Protease inhibitors (PIs);

- Entry inhibitors, which include two classes:

o Fusion inhibitors, and

o Chemokine receptor antagonists such as CCR5 antagonists; and

- Integrase inhibitors.

First-line therapeutic regimens should include a backbone of two NRTIs (listed in column A of Table 4) and a third medication consisting of an NNRTI, a PI or an integrase inhibitor (listed in column B of Table 4). Combinations of three NRTIs should be only rarely used - for instance, when interactions and side effects exclude the use of other drug classes.

The NRTI backbone should consist of tenofovir with either emtricitabine (coformulated as Truvada [Gilead Sciences, USA]) or lamivudine, or abacavir and lamivudine (coformulated as Kivexa [GlaxoSmithKline Inc, Canada]). However, both of these options may be associated with potential risks. For instance, the use of tenofovir has been associated with decreased glomerular filtration rate and tubular dysfunction, the so-called Fanconi syndrome. Although this renal toxicity has been rarely observed in published clinical trials, it has been well described in cohort studies and numerous case reports and case series. Additionally, conflicting data raise the possibility that abacavir is associated with an increased risk of myocardial infarction (31-33) or virological failure in patients with a viral load of greater than 100,000 copies/mL before initiating treatment (34). Nonetheless, randomized trials and other studies (35-38) have demonstrated no increased risk of myocardial infarction or virological failure in patients with high viral loads at inclusion with abacavir. Thus, abacavir remains a preferred option in treatmentnaive patients who are not carriers of the HLA-B*5701 allele. Caution is advised when prescribing abacavir to patients at high risk for cardiovascular events or for virological failure due to high viral loads. Backbones consisting of the older thymidine analogues, including zidovudine or stavudine, are not recommended as first-line options due to their lipodystrophic effects and increased risk of precipitating conditions such as peripheral neuropathy and lactic acidosis (39). Zidovudine is still recommended for use in pregnancy to prevent vertical transmission, unless contraindicated due to resistance, intolerance or significant anemia.

The third agent in a regimen should consist of efavirenz, raltegravir or a PI, such as atazanavir, lopinavir, fosamprenavir, saquinavir or darunavir, used in conjunction with low-dose ritonavir (ie, a boosted PI). Efavirenz has been proven effective and well tolerated when used in combination with an NRTI backbone $(40,41)$. In addition, most studies comparing efavirenz with a PI have demonstrated a lower rate of treatment failure with efavirenz (42-44), as well as a lower risk of cardiovascular events $(31,33)$. Clinical trials have shown that when boosted with ritonavir, fosamprenavir (45), saquinavir (46), atazanavir (47) and darunavir (48) were noninferior to boosted lopinavir, which is the standard comparator in PI studies due to its demonstrated benefit compared with an older unboosted PI (49), as well as its relatively large body of long-term clinical trial data. Raltegravir has been shown to be noninferior to efavirenz in two trials $(50,51)$ conducted in treatment-naive populations.

When selecting antiretroviral agents, consideration should first be given to easy-to-use combinations with proven efficacy, durability and acceptable tolerability profiles (listed as recommended combinations in Table 4). Treatment selection should also be based on the results of a genotypic resistance test, which should be conducted as early as possible in the course of HIV infection (AII). When combinations are contraindicated due to comorbidities, specific conditions or side effects, alternative combinations with poorer side effect profiles or less supporting evidence should be considered (listed as alternative combinations in Table 4). Other combinations (listed as nonrecommended combinations in Table 4) should be avoided, unless the potential benefit in a specific situation exceeds the risk. Certain antiretroviral drugs are mutually contraindicated. These combinations (listed as contraindicated combinations in Table 4) should never be used.

\section{MODIFICATIONS TO INITIAL ANTIRETROVIRAL TREATMENT}

An antiretroviral regimen may be changed to reduce or prevent side effects, facilitate adherence and in case of virological failure. Different strategies may be used depending on the desired result.

If the aim of the therapy modification is to manage side effects or improve adherence, the medication causing the problem may be replaced or the dosing regimen may be simplified.

In patients experiencing virological failure, the objective is to improve virological control. Intensification of therapy, consisting of adding only one active drug to a failing regimen, has not been shown to be effective in preventing subsequent treatment failure (52-54). Usually, the 


\begin{tabular}{|c|c|c|}
\hline & Column A: NRTI backbone & Column B: Third medication in regimen (PI, NNRTI, INI) \\
\hline \multirow[t]{7}{*}{ Recommended combinations } & $\begin{array}{l}\text { Tenofovir }^{\star \dagger}+\text { lamivudine or tenofovir } \\
\text { emtricitabine (coformulated as Truvada) }(\mathrm{Al})\end{array}$ & $\begin{array}{l}\text { Efavirenz } \mathrm{qd}^{\dagger \dagger} \text { (tenofovir + emtricitabine + efavirenz is } \\
\text { coformulated as Atripla) (Al) }\end{array}$ \\
\hline & \multirow{6}{*}{ 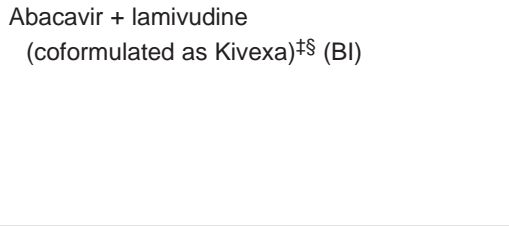 } & Atazanavir/ritonavir $\mathrm{qd}^{\dagger \ddagger \ddagger \S \S}(\mathrm{BI})$ \\
\hline & & Darunavir/ritonavir qd ${ }^{\dagger \ddagger}(\mathrm{BI})$ \\
\hline & & Fosamprenavir/ritonavir bid ${ }^{\S * \star}(\mathrm{BI})$ \\
\hline & & Lopinavir/ritonavir qd or bid ${ }^{\S}$ (coformulated as Kaletra) (BI) \\
\hline & & Saquinavir/ritonavir bid (BI) \\
\hline & & Raltegravir bid ${ }^{\dagger}(\mathrm{BI})$ \\
\hline \multirow[t]{3}{*}{ Alternative combinations } & Didanosine + lamivudine $(\mathrm{Cl})$ & Nevirapine bid ${ }^{\text {ๆा }}(\mathrm{Cl})$ \\
\hline & \multirow[t]{2}{*}{ Zidovudine + lamivudine (Cl) } & Atazanavir qd $\mathrm{d}^{\dagger \ddagger \star \star \star \star}(\mathrm{Cl})$ \\
\hline & & Fosamprenavir/ritonavir $\mathrm{qd}^{\dagger \S}(\mathrm{Cl})$ \\
\hline \multirow[t]{6}{*}{ Nonrecommended combinations } & Stavudine + didanosine (DI) & Delavirdine (DIII) \\
\hline & Stavudine + lamivudine (DI) & Indinavir (DI) \\
\hline & \multirow{4}{*}{$\begin{array}{l}\text { Zidovudine + lamivudine }+ \text { abacavir } \\
\text { (coformulated as Trizivir) (DI) }\end{array}$} & Indinavir/ritonavir (DII) \\
\hline & & Nelfinavir (DI) \\
\hline & & Ritonavir (DI) \\
\hline & & Saquinavir (DI) \\
\hline
\end{tabular}

Contraindicated combinations

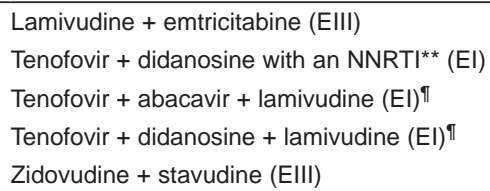

The strength of evidence is presented in parentheses. Medications in column B are presented according to class. ${ }^{*} T e n o f o v i r$ should be used with caution in patients with altered renal function or those taking concomitant nephrotoxic medications; ${ }^{\dagger}$ Insufficient data in pregnant women; ${ }^{\ddagger}$ This combination should be used when the results of the HLA-B*5701 test are negative, but it may be associated with lesser efficacy in patients with a viral load of $100,000 \mathrm{copies/mL} \mathrm{or} \mathrm{greater.} \mathrm{The} \mathrm{combina-}$ tion has not been studied in combination with darunavir/ritonavir once a day (qd), saquinavir/ritonavir or raltegravir in treatment-naive patients; $\S^{\text {May }}$ be associated with an increased risk of cardiovascular disease; "Regimens based on three nucleoside and nucleotide reverse transcriptase inhibitors (NRTIs); **The efficacy of a regimen consisting of tenofovir + didanosine + a protease inhibitor $(P I)$ is unknown. The dose of didanosine should be reduced when used concomitantly with tenofovir; ${ }^{+\dagger}$ Women of childbearing age should use effective contraception. The use of efavirenz should be avoided during pregnancy; $¥ \neq$ The association between vascular diseases and atazanavir, atazanavir/ritonavir and darunavir/ritonavir has not yet been studied; ${ }^{\S}$ Atazanavir should always be boosted with ritonavir if used with tenofovir; "Tevirapine is considered to be an alternative solution for women with CD4 counts of lower than 250 cells/ $\mu$ L and for men with CD4 counts of lower than 400 cells/ $\mu$ L. Nevirapine should not be initiated in individuals with higher CD4 counts, unless the benefits clearly exceed the risk; ***Unboosted atazanavir should not be used with didanosine + lamivudine (111). Atripla (Bristol-Myers Squibb, USA; and Gilead Sciences, USA); Kaletra (Abbott Laboratories, USA); Kivexa (GlaxoSmithKline Inc, Canada); Trizivir (GlaxoSmithKline Inc, Canada); Truvada (Gilead Sciences, USA). bid Twice a day; INI Integrase inhibitors; NNRTIs Nonnucleoside reverse transcriptase inhibitors

presence of resistance mutations in these patients requires that some or all of the current antiretrovirals in the therapeutic regimen be replaced by active drugs.

Treatment interruptions in aviremic patients

Evidence shows that persons living with HIV experience clinical disease progression when antiretroviral treatment is interrupted $(55,56)$. For this reason, treatment interruptions are not recommended in clinical practice (DI).

However, if treatment must be stopped, it is safer to do so in asymptomatic patients with no history of syndromes indicative of AIDS and in patients with a nadir CD4 count of greater than 350 cells/ $\mu \mathrm{L}$ (CII) (57-59). If the patient's regimen contains an NNRTI, the NNRTI may be replaced by a boosted active PI for a period of as long as four weeks before interrupting therapy to avoid functional monotherapy and prevent the emergence of resistance mutations to NNRTIs due to their long half-life and low genetic barrier to resistance (CIII) (55,56,60-62). Patients require careful follow-up involving clinical evaluation, CD4 cell count, measurement of HIV viral load and genotypic testing during the interruption period (BII). Patients should also be advised regarding the risks of occurrence of opportunistic infection, HIV primary infection syndrome, disease progression with rapid decrease in CD4 count and elevation of HIV viral load, transmission of HIV and development of viral resistance. Medication should be resumed at a CD4 count of higher than 250 cells/ $\mu \mathrm{L}$ (BII), although the safe threshold for resuming treatment has yet to be determined and is probably as high as 350 cells/ $\mu \mathrm{L}(56,57)$.

\section{Switching antiretroviral agents}

Antiretroviral therapy may be associated with adverse effects in some patients; various alternative strategies have been shown to reduce certain side effects. Switching from one boosted PI to another may simplify the dosing regimen or reduce certain side effects (63-66). For example, switching from a PI other than darunavir to atazanavir, boosted atazanavir, nevirapine, abacavir or raltegravir may improve the lipid profile and reduce hyperlipidemia $(67-74)$. However, the noninferiority of raltegravir has not yet been demonstrated with regard to switches from a PI to raltegravir, particularly in patients with previous therapeutic failures (74). For this reason, switching from a PI to raltegravir should be avoided in cases of previous failure, NRTI resistance acquired during primary infection or exposure to suboptimal monotherapy or dual therapy. Similarly, switching from a PI to abacavir should be avoided under the same circumstances because such switches have been shown to occasionally result in a resurgence of viremia $(69,71,75)$. In the absence of more conclusive data, the same precautions are warranted for switching from a PI to an NNRTI or unboosted atazanavir. On the other hand, switching from enfuvirtide to raltegravir in treatment-experienced patients, whose current regimen fully suppresses viral activity, maintains viral suppression and improves patient quality of life (76). 


\section{TABLE 5}

Therapies to consider based on the type of regimen failed

\begin{tabular}{|c|c|}
\hline Type of regimen failed & Therapy for treatment-experienced patients \\
\hline \multirow[t]{2}{*}{ Three NRTIs } & Two active NRTIs + one boosted PI \\
\hline & Two NRTIs with residual activity, one boosted PI + one NNRTI \\
\hline NRTIS + NNRTI & Two active NRTIs + one boosted PI \\
\hline \multirow[t]{3}{*}{ NRTIs + PI or boosted PI } & $\begin{array}{l}\text { Two NRTIs + one boosted PI to which the virus remains susceptible including, as necessary, boosted darunavir or boosted } \\
\text { tipranavir for patients demonstrating extensive resistance to other PIs }\end{array}$ \\
\hline & Two fully active NRTIs + one NNRTI \\
\hline & Two NRTIs + one boosted PI + one NNRTI \\
\hline \multirow[t]{5}{*}{ NRTI + PI + NNRTI } & $\begin{array}{l}\text { Two active NRTIs + one boosted PI to which the virus remains susceptible including, as necessary, boosted darunavir or } \\
\text { boosted tipranavir for patients demonstrating extensive resistance to other PIs }\end{array}$ \\
\hline & $\begin{array}{l}\text { Etravirine + NRTI + darunavir/ritonavir for patients demonstrating resistance to other PIs; lopinavir/ritonavir or saquinavir/ } \\
\text { ritonavir may be used as alternative boosted PIs }\end{array}$ \\
\hline & $\begin{array}{l}\text { Use maraviroc (in patients with R5-tropic virus) and raltegravir as necessary with NRTIs, new generation PIs and/or } \\
\text { enfuvirtide to establish a therapeutic regimen including at least two and, if possible, three active medications }\end{array}$ \\
\hline & $\begin{array}{l}\text { There are no data on the relevance of maintaining NRTIs or PIs in the regimen in cases of extensive resistance to these } \\
\text { agents }\end{array}$ \\
\hline & Use investigational therapies as necessary to establish an active therapeutic regimen \\
\hline
\end{tabular}

NNRTI Non-nucleoside reverse transcriptase inhibitors; NRTI Nucleoside and nucleotide reverse transcriptase inhibitors; PI Protease inhibitor

Thymidine analogues, such as stavudine and zidovudine, are associated with an increased risk of lipoatrophy and lactic acidemia (77), and switching from these drugs to abacavir or tenofovir can partially reverse or prevent these conditions (78-84). However, switching from a thymidine analogue to abacavir may theoretically increase the risk of cardiovascular disease $(31,33,85)$. Thus, when considering switching antiretroviral agents to improve adherence or quality of life, the risks and benefits of the proposed modifications should be carefully considered. It is also important to ensure that the new therapeutic regimen maintains the genetic barrier to resistance and does not entail drug interactions that could compromise an antiretroviral agent's effectiveness.

\section{Regimen changes after virological failure}

Since 2002, the incidence of virological treatment failure has decreased in the developed world, possibly because of access to simpler and better tolerated therapies and the greater emphasis placed on adherence $(86,87)$. Despite this improvement, the emergence of drugresistant viral strains remains an issue in the treatment of persons living with HIV.

In cases of suspected virological failure, it is important to confirm treatment failure by taking a second viral load measurement (AII). Virological failure is defined by many experts as a viral load of greater than 1000 copies $/ \mathrm{mL}$ after 16 weeks of treatment, 400 copies $/ \mathrm{mL}$ after 24 weeks of treatment or 50 copies $/ \mathrm{mL}$ after 48 weeks of treatment. The cause of the failure should be determined by assessing the patient's adherence to therapy and, if necessary and possible, by measuring plasma levels of PIs and NNRTIs to evaluate whether pharmacokinetic factors are contributing to treatment failure. HIV genotypic testing should also be undertaken, and results should be interpreted taking into account both the patient's past therapies and the results of previous genotypic tests. When the use of a CCR 5 antagonist is being considered, tropism testing is also required. The results of these tests, in conjunction with the patient's history of therapeutic regimens, comorbidities and adverse events, can then be used to determine viable therapeutic options to control viral replication.

As with first-line treatment, the goal of a second-line regimen is to achieve and maintain viral suppression, as indicated by a viral load of consistently less than 50 copies $/ \mathrm{mL}$. At least two active drugs should be included in any regimen (AI), and three active drugs should be used when possible (AI). When only partially active drugs are included in the regimen, more than three drugs might be required for complete viral suppression. New classes of antiretrovirals may be combined as required to achieve this goal. However, using a drug from a new class as the only active medication in a regimen (DII) should be avoided, unless the patient's condition is seriously compromised in the short term (CIII).

The specific types of medications included in a second-line regimen will likely depend on the patient's previous regimen (Table 5). In patients failing a regimen including only NRTIs, studies (88) have demonstrated the effectiveness of regimens consisting of a PI and two new NRTIs with no cross-resistance to previously failed NRTIs or a boosted PI, one NNRTI and two NRTIs with residual activity. Studies $(89,90)$ evaluating treatment options in patients failing first-line therapy consisting of NRTIs and an NNRTI suggest that a regimen of a boosted PI and active NRTIs is effective in this population. Regimens including two active NRTIs and an active boosted PI with or without an NNRTI may be considered for patients who failed a PI-based regimen (89-97).

Various therapeutic options are now available, even for patients who failed treatment using the three traditional classes of antiretroviral therapy (Table 5). Newer boosted PIs, such as darunavir and tipranavir, provide an alternative for some patients with extensive resistance to other PIs $(98,99)$. Similarly, etravirine is a new NNRTI that, when used with a boosted active PI such as darunavir, lopinavir or saquinavir and other active drugs, has been shown to effectively suppress viral replication in patients resistant to first-generation NNRTIs and the two other traditional classes of drugs but with no significant resistance to etravirine $(100,101)$. Other options shown to be effective in such treatment-experienced patients include antiretroviral agents from new classes, such as maraviroc (used in patients with R5-tropic virus) (102), raltegravir (103-105) and enfuvirtide (106,107). These new classes of antiretrovirals may be combined with NRTIs, PIs or new generation NNRTIs to establish a therapeutic regimen that includes at least two, and possibly three, active molecules (AI). When attempting to establish an active therapeutic regimen, it is recommended to consult an expert to explore access to new medications through clinical trials or compassionate access programs (CIII).

If it becomes necessary to select from drugs with compromised antiviral activity, well-tolerated antiretrovirals with residual antiviral activity or the ability to decrease viral replication (CIII) should be chosen. Interrupting treatment is not recommended in patients who have experienced virological failure. Clinical progression has been observed in studies evaluating this strategy $(108,109)$. However, if a patient must take a drug holiday and is harbouring a virus with an M184V resistance mutation, retaining lamivudine as monotherapy is preferable to complete cessation of therapy, because this may have a beneficial effect on virological and immunological parameters (CI) (110). 


\section{CONCLUSIONS}

By suppressing viral replication and maintaining adequate CD4 levels, antiretroviral therapy reduces morbidity and mortality. A therapeutic regimen consisting of three active antiretroviral agents is considered to be the most effective way to achieve this goal, and should be initiated in patients presenting with AIDS, serious clinical symptoms related to HIV, HIV-associated nephropathy, coinfection with HBV when treatment of hepatitis or HIV is required, pregnancy or a CD4 count of less than 350 cells $/ \mu \mathrm{L}$. Medications should be selected taking into consideration the medications' effectiveness and tolerability profiles, as well as the patient's concomitant conditions and treatment history. Treatment interruption is associated with clinical progression and should generally be avoided in both aviremic patients and those experiencing virological failure. Instead, the therapeutic regimen should be adjusted as necessary to minimize side effects, promote adherence and achieve a viral load of less than 50 copies $/ \mathrm{mL}$.

ACKNOWLEDGEMENTS: The authors thank Marie Courchesne, Josianne Gauthier, Danielle Gourde, Niamh Higgins, Suzanne Marcotte, Stéphane Roux, Nancy Sheehan and Rachel Therrien for their participation in the guidelines writing committee and their contributions to the development of this document. They also thank Dr Patrice Junod, Dr Bernard Lessard, Ken Monteith, Dr Alain Piché, Dr Cécile Tremblay, Dr Sylvie Trottier and Dr Chris Tsoukas, who serve on the Comité consultatif sur la prise en charge clinique des personnes vivant avec le VIH.

POTENTIAL CONFLICTS OF INTEREST: Dr Danielle Rouleau has received consultancy fees from Abbott, GlaxoSmithKline and Tibotec, honoraria from Gilead, Merck and Tibotec and grant support from Abbott, Bristol-Myers Squibb, Gilead, GlaxoSmithKline, Merck, Pfizer, Roche, Tibotec and ViiV. Dr Claude Fortin has received honoraria from Gilead and Tibotec and grant support from Gilead and Pfizer. Dr Benoît Trottier has received consultancy fees from Abbott, Boehringer Ingelheim, Bristol-Myers Squibb, Gilead, GlaxoSmithKline, Merck, Pfizer, Roche and Tibotec. Dr Richard Lalonde has received consultancy fees from Abbott, Merck, Schering-Plough and Tibotec, honoraria from Abbott, Tibotec and ViiV and grant support from Abbott, Boehringer Ingelheim, Bristol-Myers Squibb, GlaxoSmithKline, Merck, Pfizer, Schering-Plough, ViiV and Virochem Pharma. Dr Normand Lapointe has received consultancy fees from Boehringer Ingelheim, honoraria from Abbott and grant support from Tibotec. Dr Pierre Côté has received consultancy fees from Abbott, Bristol-Myers Squibb, GlaxoSmithKline, Merck and Pfizer and honoraria from Abbott, Boehringer Ingelheim, Bristol-Myers Squibb, Gilead, GlaxoSmithKline, Merck, Pfizer, Schering-Plough and ViiV. Dr Jean-Pierre Routy has received consultancy fees and honoraria from Abbott, Bristol-Myers Squibb, Gilead, GlaxoSmithKline, Merck, Tibotec and ViiV. MarieFrance Matte and Irina Tsarevsky have no potential conflicts of interest to declare. Dr Jean-Guy Baril has received grant support from Abbott, Bristol-Myers Squibb, Boehringer Ingelheim, Gilead, GlaxoSmithKline, Merck, Pfizer, Roche and Tibotec, and honoraria and consultancy fees from Abbott, Bristol-Myers Squibb, Boehringer Ingelheim, Gilead, GlaxoSmithKline, Merck, Pfizer and Tibotec. The English-language translation of the present article was partially supported by unrestricted grants from several pharmaceutical companies.

\section{REFERENCES}

1. Panel on Antiretroviral Guidelines for Adults and Adolescents. Guidelines for the use of antiretroviral agents in HIV-1-infected adults and adolescents. Washington, DC: U.S. Department of Health and Human Services, 2008.

2. Vernazza P, Hirschel B, Bernasconi E, Flepp M. Les personnes séropositives ne souffrant d'aucune autre MST et suivant un traitement antirétroviral efficace ne transmettent pas le VIH par voie sexuelle. Bull Med Suisses 2008;89:165-70.
3. Bruneau A, Baril J-G, Bruneau J, et al. Guide pour la prophylaxie après une exposition au VIH, au VHB et au VHC dans un contexte non professionnel. Québec: Ministère de la Santé et des Services sociaux, 2010. (In press)

4. Reynolds S, Makumbi F, Kagaayi J, et al. ART reduced the rate of sexual transmission of HIV among HIV-discordant couples in rural Rakai, Uganda. 16th Conference on Retroviruses and Opportunistic Infections. Montreal, February 8 to 11, 2009. (Abst)

5. Sullivan P, Kayitenkore K, Chomba E, et al. Reduction of HIV transmission risk and high risk sex while prescribed ART: Results from discordant couples in Rwanda and Zambia. 16th Conference on Retroviruses and Opportunistic Infections. Montreal, February 8 to 11,2009 . (Abst)

6. Sheth P, Kovacs C, Kemal K, et al. Persistent HIV RNA shedding in semen despite effective ART. 16th Conference on Retroviruses and Opportunistic Infections. Montreal, February 8 to 11, 2009. (Abst)

7. Marcelin A-G, Tubiana R, Lambert-Niclot S, et al. Detection of HIV-1 RNA in seminal plasma samples from treated patients with undetectable HIV-1 RNA in blood plasma. 16th Conference on Retroviruses and Opportunistic Infections. Montreal, February 8 to 11, 2009. (Abst)

8. Neely MN, Brening L, Xu J, et al. Cervical shedding of HIV-1 RNA among women with low levels of viremia while receiving highly active antiretroviral therapy. J Acquir Immune Defic Syndr 2007;44:38-42.

9. U.S. Department of Health and Human Services. Antiretroviral postexposure prophylaxis after sexual, injection-drug use, or other nonoccupational exposure to HIV in the United States. MMWR 2005;54:1-20

10. Phillips A, Pezzotti P, CASCADE Collaboration. Short-term risk of AIDS according to current CD4 cell count and viral load in antiretroviral drug-naive individuals and those treated in the monotherapy era. AIDS 2004;18:51-8.

11. May M, Sterne JA, Sabin C, et al. Prognosis of HIV-1-infected patients up to 5 years after initiation of HAART: Collaborative analysis of prospective studies. AIDS 2007;21:1185-97.

12. Sterling TR, Chaisson RE, Keruly J, Moore RD. Improved outcomes with earlier initiation of highly active antiretroviral therapy among HIV infected patients who achieve durable virologic suppression: Longer follow-up of an observational cohort study. J Infect Dis 2003;188:1659-65.

13. Egger M, May M, Chêne G, et al. Prognosis of HIV-1-infected patients starting highly active antiretroviral therapy: A collaborative analysis of prospective studies. Lancet 2002;360:119-29.

14. Moore RD, Keruly JC. CD4+ cell count 6 years after commencement of highly active antiretroviral therapy in persons with sustained virologic suppression. Clin Infect Dis 2007:44:441-6

15. Hogg RS, Heath KV, Yip B, et al. Improved survival among HIV-infected individuals following initiation of antiretroviral therapy. JAMA 1998;279:450-4.

16. Palella FJ, Delaney KM, Moorman AC, et al. Declining morbidity and mortality among patients with advanced human immunodeficiency virus infection. HIV outpatient study investigators. N Engl J Med 1998;338:853-60.

17. Palella FJ, Deloria-Knoll M, Chmiel JS, et al. Survival benefit of initiating antiretroviral therapy in HIV-infected persons in different CD4+ cell strata. Ann Intern Med 2003;138:620-6.

18. When To Start Consortium, Sterne JA, May M, et al. Timing of initiation of antiretroviral therapy in AIDS-free HIV-1-infected patients: A collaborative analysis of 18 HIV cohort studies. Lancet 2009;373:1352-63.

19. Jaén Á, Esteve A, Miró JM, et al. Determinants of HIV progression and assessment of the optimal time to initiate highly active antiretroviral therapy: PISCIS Cohort (Spain). J Acquir Immune Defic Syndr 2008;47:212-20.

20. Kitahata MM, Gange S, Moore R; North American AIDS Cohort Collaboration on RES and Design. Initiating rather deferring HAART at a CD4+ count $>500$ cells $/ \mathrm{mm}^{3}$ is associated with improved survival. 16th Conference on Retroviruses and Opportunistic Infections. Montreal, February 8 to 11, 2009. (Abst)

21. Hocqueloux L, Avettand-Fènoël V, Jacquot S, et al. Better HIV-1 DNA depletion and CD4 restoration with HAART initiated at the time of primary HIV infection than with HAART started during chronic HIV infection. 16th Conference on Retroviruses and Opportunistic Infections. Montreal, February 8 to 11, 2009. (Abst) 
22. Lichtenstein $\mathrm{K}$, Armon C, Buchacz K, et al. Initiation of antiretroviral therapy at CD4 cell counts $\geq 350$ cells $/ \mathrm{mm}^{3}$ does not increase incidence or risk of peripheral neuropathy, anemia, or renal insufficiency. J Acquir Immune Defic Syndr 2008;47:27-35.

23. Mellors JW, Muñoz A, Giorgi JV, et al. Plasma viral load and CD4+ lymphocytes as prognostic markers of HIV-1 infection. Ann Intern Med 1997;126:946-54.

24. Phair JP, Mellors JW, Detels R, Margolick JB, Muñoz A. Virologic and immunologic values allowing safe deferral of antiretroviral therapy. AIDS 2002;16:2455-9.

25. Benhamou Y, Bochet M, Di Martino V, et al. Liver fibrosis progression in human immunodeficiency virus and hepatitis $C$ virus coinfected patients. The Multivirc Group. Hepatology 1999;30:1054-8.

26. Puoti M, Bonacini M, Spinetti A, et al. Liver fibrosis progression is related to CD4 cell depletion in patients coinfected with hepatitis $\mathrm{C}$ virus and human immunodeficiency virus. J Infect Dis 2001;183:134-7.

27. Atta MG, Gallant JE, Rahman MH, et al. Antiretroviral therapy in the treatment of HIV-associated nephropathy.

Nephrol Dial Transplant 2006;21:2809-13.

28. Schwartz EJ, Szczech LA, Ross MJ, Klotman ME, Winston JA, Klotman PE. Highly active antiretroviral therapy and the epidemic of HIV+ end-stage renal disease. J Am Soc Nephrol 2005;16:2412-20.

29. Klein M, Baril JG, Charron MA, Fortin C, et al. La prise en charge et le traitement des personnes co-infectées par le virus de l'immunodéficience humaine (VIH) et le virus de l'hépatite B (VHB). Québec: Ministère de la Santé et des Services sociaux, 2010. (In press)

30. Hirsch MS. Initiating therapy: When to start, what to use. J Infect Dis 2008:197:S252-60.

31. D:A:D Study Group, Sabin CA, Worm SW, et al. Use of nucleoside reverse transcriptase inhibitors and risk of myocardial infarction in HIV-infected patients enrolled in the D:A:D study: A multi-cohort collaboration. Lancet 2008;371:1417-26.

32. Strategies for Management of Anti-Retroviral Therapy/INSIGHT; DAD Study Groups. Use of nucleoside reverse transcriptase inhibitors and risk of myocardial infarction in HIV-infected patients. AIDS 2008;12:F17-24.

33. Lang S, Mary-Krause M, Cotte L, et al. Impact of specific NRTI and PI exposure on the risk of myocardial infarction: A case-control study nested within FHDH ANRS CO4. 16th Conference on Retroviruses and Opportunistic Infections. Montréal, February 8 to 11,2009 . (Abst)

34. Sax P, Tierney C, Collier A, et al. ACTG 5202: Shorter time to virologic failure (VF) with abacavir/lamivudine (ABC/3TC) than tenofovir/emtricitabine (TDF/FTC) as part of combination therapy in treatment-naïve subjects with screening HIV RNA $\geq 100,000 \mathrm{c} / \mathrm{mL}$. XVII International AIDS Conference. Mexico City, August 3 to 8, 2008. (Abst)

35. Smith KY, Patel P, Fine D, et al. Randomized, double-blind, placebo-matched, multicenter trial of abacavir/lamivudine or tenofovir/emtricitabine with lopinavir/ritonavir for initial HIV treatment. AIDS 2009;23:1547-56.

36. Pappa K, Hernandez J, Ha B, et al. Abacavir/lamivudine (ABC/3TC) shows robust virologic responses in ART-naïve patients for baseline (BL) viral loads (VL) of $>100,000 \mathrm{c} / \mathrm{mL}$ and $<100,000 \mathrm{c} / \mathrm{mL}$ by endpoint used in ACTG5202. XVII International AIDS Conference. Mexico City, August 3 to 8, 2008. (Abst)

37. Brothers CH, Hernandez JE, Cutrell AG, et al. Risk of myocardial infarction and abacavir therapy: No increased risk across 52 GlaxoSmithKline-sponsored clinical trials in adult subjects. J Acquir Immune Defic Syndr 2009;51:20-8.

38. Benson C, Ribaudo H, Zheng E, et al. No association of abacavir use with risk of myocardial infarction or severe cardiovascular disease events: results from ACTG A5001. 16th Conference on Retroviruses and Opportunistic Infections. Montreal, February 8 to 11,2009 . (Abst)

39. Haubrich RH, Riddler SA, DiRienzo AG, et al. Metabolic outcomes in a randomized trial of nucleoside, nonnucleoside and protease inhibitor-sparing regimens for initial HIV treatment. AIDS 2009;23:1109-18.

40. Gallant JE, DeJesus E, Arribas JR, et al. Tenofovir DF, emtricitabine, and efavirenz vs. zidovudine, lamivudine, and efavirenz for HIV. N Engl J Med 2006;354:251-60.

41. Podzamczer D, Ferrer E, Sanchez P, et al. Less lipoatrophy and better lipid profile with abacavir as compared to stavudine: 96-week results of a randomized study. J Acquir Immune Defic Syndr 2007;44:139-47.
42. Riddler SA, Haubrich R, DiRienzo AG, et al. Class-sparing regimens for initial treatment of HIV-1 infection. N Engl J Med 2008;358:2095-106.

43. Bartlett JG, Johnson J, Herrera G, et al. Long-term results of initial therapy with abacavir and lamivudine combined with efavirenz, amprenavir/ritonavir, or stavudine. J Acquir Immune Defic Syndr 2006;43:284-92.

44. Montaner JS, Schutz M, Schwartz R, et al. Efficacy, safety and pharmacokinetics of once-daily saquinavir soft-gelatin capsule/ ritonavir in antiretroviral-naive, HIV-infected patients. MedGenMed 2006;8:36.

45. Eron J Jr, Yeni P, Gathe J Jr, et al. The KLEAN study of fosamprenavir/ritonavir versus lopinavir/ritonavir, each in combination with abacavir-lamivudine, for initial treatment of HIV infection over 48 weeks: A randomised non-inferiority trial. Lancet 2006;368:476-82.

46. Walmsley S, Avihingsanon A, Slim J, et al. Gemini: A noninferiority study of saquinavir/ritonavir versus lopinavir/ritonavir as initial HIV-1 therapy in adults. J Acquir Immune Defic Syndr 2009;50:367-74.

47. Molina J-M, Andrade-Villanueva J, Echevarria J, et al. Once-daily atazanavir/ritonavir versus twice-daily lopinavir/ritonavir, each in combination with tenofovir and emtricitabine, for management of antiretroviral-naive HIV-1-infected patients: 48 week efficacy and safety results of the CASTLE study. Lancet 2008;372:646-55.

48. Ortiz R, Dejesus E, Khanlou H, et al. Efficacy and safety of once-daily darunavir/ritonavir versus lopinavir/ritonavir in treatment-naive HIV-1-infected patients at week 48. AIDS 2008;22:1389-97.

49. Walmsley S, Bernstein B, King M, et al. Lopinavir-ritonavir versus nelfinavir for the initial treatment of HIV infection. N Engl J Med 2002;346:2039-46.

50. Markowitz M, Nguyen BY, Gotuzzo E, et al. Sustained antiretroviral effect of raltegravir after 96 weeks of combination therapy in treatment-naive patients with HIV-1 infection. J Acquir Immune Defic Syndr 2009;52:350-6.

51. Lennox JL, DeJesus E, Lazzarin A, et al. Safety and efficacy of raltegravir-based versus efavirenz-based combination therapy in treatment-naive patients with HIV-1 infection: A multicentre, double-blind randomised controlled trial. Lancet 2009;374:796-806.

52. Schooley RT, Ruane P, Myers RA, et al. Tenofovir DF in antiretroviral-experienced patients: Results from a 48-week, randomized, double-blind study. AIDS 2002;16:1257-63.

53. Squires K, Pozniak AL, Pierone G Jr, et al. Tenofovir disoproxil fumarate in nucleoside-resistant HIV-1 infection: A randomized trial. Ann Intern Med 2003;139:313-20.

54. Molina J-M, Marcelin AG, Pavie J, et al. Didanosine in HIV-1infected patients experiencing failure of antiretroviral therapy: A randomized placebo-controlled trial. J Infect Dis 2005;191:830-9.

55. Danel C, Moh R, Minga A, et al. CD4-guided structured antiretroviral treatment interruption strategy in HIV-infected adults in west Africa (Trivacan ANRS 1269 trial): A randomized trial. Lancet 2006;367:1981-9.

56. Strategies for Management of AntiRetroviral Therapy (SMART) Study Group, El-Sadr WM, Lundgren JD, et al. CD4+ count-guided interruption of antiretroviral treatment. N Engl J Med 2006;355:2283-96.

57. Mussini C, Bedini A, Borghi V, et al. CD4 cell-monitored treatment interruption in patients with a CD4 cell count $>500 \times 10^{6}$ cells/l. AIDS 2005;19:287-94.

58. Maggiolo F, Ripamonti D, Gregis G, Quinzan G, Callegaro A, Suter F. Effect of prolonged discontinuation of successful antiretroviral therapy on CD4 T cells: A controlled, prospective trial. AIDS 2004;18:439-46.

59. Fernández Guerrero ML, Rivas P, Molina M, Garcia R, De Górgolas M. Long-term follow-up of asymptomatic HIV-infected patients who discontinued antiretroviral therapy. Clin Infect Dis 2005;41:390-4.

60. Taylor S, Fisher M, Jayasuriya A, et al. Kaletra single agent therapy as a universal ART stopping strategy: The STOP 2 study. 10th International Workshop on Clinical Pharmacology of HIV Therapy. Amsterdam, April 15 to 17, 2009. (Abst)

61. Palmisano L, Giuliano M, Bucciardini R, et al. Determinants of virologic and immunologic outcomes in chronically HIV-infected subjects undergoing repeated treatment interruptions: The Istituto Superiore di Sanita-Pulsed Antiretroviral Therapy (ISS-PART) study. J Acquir Immune Defic Syndr 2007;46:39-47. 
62. Fox Z, Phillips A, Cohen C, et al. Viral resupression and detection of rug resistance following interruption of a suppressive non-nucleoside reverse transcriptase inhibitor-based regimen. AIDS 2008;22:2279-89.

63. Arnaiz JA, Mallolas J, Podzamczer D, et al. Continued indinavir versus switching to indinavir/ritonavir in HIV-infected patients with suppressed viral load. AIDS 2003;17:831-40.

64. Cardiello PG, van Heeswijk RP, Hassink EA, et al. Simplifying protease inhibitor therapy with once-daily dosing of saquinavir soft-gelatin capsules/ritonavir (1600/100 mg): HIVNAT 001.3 study. J Acquir Immune Defic Syndr 2002;29:464-70.

65. Sprinz E, Neto AJ, Bargman E, et al. Substitution with lopinavir/ ritonavir improves patient-reported outcomes including quality of life in patients who were intolerant to their antiretroviral therapy. HIV Clin Trials 2006;7:291-308.

66. Wood RS, Phanuphak P, Cahn P, et al. Long-term efficacy and safety of atazanavir with stavudine and lamivudine in patients previously treated with nelfinavir or atazanavir. J Acquir Immune Defic Syndr 2004;36:684-92.

67. Moyle G, Girard J, Andrade J, et al. Continuation of BID boosted PI vs switch to once-daily ATV/RTV for the management of lipodystrophy: 48 week primary analysis of the 96 week multicenter, open-label, randomized, prospective ReAL study. XVII International AIDS Conference. Mexico City, August 3 to 8, 2008. (Abst)

68. Negredo E, Cruz L, Paredes R, et al. Virological, immunological, and clinical impact of switching from protease inhibitors to nevirapine or to efavirenz in patients with human immunodeficiency virus infection and long-lasting viral suppression. Clin Infect Dis 2002;34:504-10.

69. Maggiolo F, Ripamonti D, Ravasio L, et al. Outcome of 2 simplification strategies for the treatment of human immunodeficiency virus type 1 infection. Clin Infect Dis 2003;37:41-9.

70. Ruiz L, Negredo E, Domingo P, et al. Antiretroviral treatment simplification with nevirapine in protease inhibitor-experienced patients with HIV-associated lipodystrophy: 1-year prospective follow-up of a multicenter, randomized, controlled study. J Acquir Immune Defic Syndr 2001;27:229-36.

71. Opravil M, Hirschel B, Lazzarin A, et al. A randomized trial of simplified maintenance therapy with abacavir, lamivudine, and zidovudine in human immunodeficiency virus infection. J Infect Dis 2002;185:1251-60.

72. Clumeck N, Goebel F, Rozenbaum W, et al. Simplification with abacavir-based triple nucleoside therapy versus continued protease inhibitor-based highly active antiretroviral therapy in HIV-1-infected patients with undetectable plasma HIV-1 RNA. AIDS 2001;15:1517-26.

73. Katlama C, Fenske S, Gazzard B, et al. TRIZAL study: Switching from successful HAART to Trizivir (abacavir-lamivudine-zidovudine combination tablet): 48 weeks efficacy, safety and adherence results. HIV Med 2003;4:79-86.

74. Eron J, Andrade J, Zajdenverg R, et al. Switching from stable lopinavir/ritonavir-based to raltegravir-based combination ART resulted in a superior lipid profile at week 12 but did not demonstrate non-inferior virologic efficacy at week 24 .

16th Conference on Retroviruses and Opportunistic Infections. Montreal, February 8 to 11, 2009. (Abst)

75. Martínez E, Arnaiz JA, Podzamczer D, et al. Substitution of nevirapine, efavirenz, or abacavir for protease inhibitors in patients with human immunodeficiency virus infection. N Engl J Med 2003;349:1036-46.

76. De Castro N, Braun J, Charreau I, et al. Switch from enfuvirtide to raltegravir in highly treatment-experienced HIV-1-infected patients: A randomized open-label non-inferiority trial, Easier - ANRS 138. 16th Conference on Retroviruses and Opportunistic Infections. Montreal, February 8 to 11, 2009. (Abst)

77. Baril J-G, Junod P, Leblanc R, et al. HIV-associated lipodystrophy syndrome: A review of clinical aspects. Can J Infect Dis Med Microbiol 2005;16:233-43.

78. Carr A, Workman C, Smith DE, et al. Abacavir substitution for nucleoside analogs in patients with HIV lipoatrophy: A randomized trial. JAMA 2002;288:207-15.

79. McComsey GA, Ward DJ, Hessenthaler SM, et al. Improvement in lipoatrophy associated with highly active antiretroviral therapy in human immunodeficiency virus-infected patients switched from stavudine to abacavir or zidovudine: The results of the TARHEEL study. Clin Infect Dis 2004;38:263-70.
80. Moyle G, Sabin CA, Cartledge J, et al. A randomized comparative trial of tenofovir DF or abacavir as replacement for a thymidine analogue in persons with lipoatrophy. AIDS 2006;20:2043-50.

81. Milinkovic A, Martinez E, López S, et al. The impact of reducing stavudine dose versus switching to tenofovir on plasma lipids, body composition and mitochondrial function in HIV-infected patients. Antivir Ther 2007;12:407-15.

82. Martínez E, Ribera E, Pulido F, et al. Early improvement of limb fat content in patients switching from AZT/3TC to FTC/TDF (TVD): A 24 week interim analysis of the RECOMB trial. XVII International AIDS Conference. Mexico City, August 3 to 8, 2008. (Abst)

83. Fisher M, Moyle GJ, Shahmanesh M, et al. A randomized comparative trial of continued zidovudine/lamivudine or replacement with tenofovir disoproxil fumarate/emtricitabine in efavirenz-treated HIV-1-infected individuals. J Acquir Immune Defic Syndr 2009;51:562-8.

84. Martínez E, Arranz JA, Podzamczer D, et al. A simplification trial switching from nucleoside reverse transcriptase inhibitors to once-daily fixed-dose abacavir/lamivudine or tenofovir/emtricitabine in HIV-1-infected patients with virological suppression. J Acquir Immune Defic Syndr 2009;51:290-7.

85. Cooper D, Bloch M, Humphries A, et al. Simplification with fixed-dose tenofovir/emtricitabine or abacavir/lamivudine in adults with suppressed HIV replication: The STEAL study, a randomized, open-label, 96-week, non-inferiority trial. 16th Conference on Retroviruses and Opportunistic Infections. Montreal, February 8 to 11, 2009. (Abst)

86. Lohse N, Obel N, Kronborg G, et al. Declining risk of triple-class antiretroviral drug failure in Danish HIV-infected individuals. AIDS 2005; 19:815-22.

87. Moore RD, Keruly JC, Gebo KA, Lucas GM. An improvement in virologic response to highly active antiretroviral therapy in clinical practice from 1996 through 2002. J Acquir Immune Defic Syndr 2005;39:195-8.

88. Albrecht M, Bosch RJ, Hammer SM, et al. Nelfinavir, efavirenz, or both after the failure of nucleoside treatment of HIV infection. N Engl J Med 2001;345:398-407.

89. Shafer RW, Smeaton LM, Robbins GK, et al. Comparison of four-drug regimens and pairs of sequential three-drug regimens as initial therapy for HIV-1 infection. N Engl J Med 2003;349:2304-15.

90. Ruxrungtham K, Pedro RJ, Latiff GH, et al. Impact of reverse transcriptase resistance on the efficacy of TMC125 (etravirine) with two nucleoside reverse transcriptase inhibitors in protease inhibitor-naïve, nonnucleoside reverse transcriptase inhibitorexperienced patients: Study TMC125-C227. HIV Med 2008;9:883-96.

91. Gulick RM, Hu XJ, Fiscus SA, et al. Randomized study of saquinavir with ritonavir or nelfinavir together with delavirdine, adefovir, or both in human immunodeficiency virus-infected adults with virologic failure on indinavir: AIDS Clinical Trials Group Study 359. J Infect Dis 2000;182:1375-84.

92. Hammer SM, Vaida F, Bennett KK, et al. Dual vs single protease inhibitor therapy following antiretroviral treatment failure: A randomized trial. JAMA 2002;288:169-80.

93. Robbins GK, De Gruttola V, Shafer RW, et al. Comparison of sequential three-drug regimens as initial therapy for HIV-1 infection. N Engl J Med 2003;349:2293-303.

94. Cohen C, Nieto-Cisneros L, Zala C, et al. Comparison of atazanavir with lopinavir/ritonavir in patients with prior protease inhibitor failure: A randomized multinational trial. Curr Med Res Opin 2005;21:1683-92.

95. Johnson M, Grinsztejn B, Rodriguez C, et al. Atazanavir plus ritonavir or saquinavir, and lopinavir/ritonavir in patients experiencing multiple virological failures. AIDS 2005;19:685-94.

96. Dragsted UB, Gerstoft J, Youle M, et al. A randomized trial to evaluate lopinavir/ritonavir versus saquinavir/ritonavir in HIV-1-infected patients: The MaxCmin2 trial. Antivir Ther 2005;10:735-43.

97. Madruga JV, Berger D, McMurchie M, et al. Efficacy and safety of darunavir-ritonavir compared with that of lopinavir-ritonavir at 48 weeks in treatment-experienced, HIV-infected patients in TITAN: A randomised controlled phase III trial. Lancet 2007;370:49-58.

98. Hicks C, Cahn P, Cooper DA, et al. Durable efficacy of tipranavir-ritonavir in combination with an optimised background regimen of antiretroviral drugs for treatment-experienced HIV-1-infected patients at 48 weeks in the randomized evaluation of strategic intervention in multi-drug resistant patients with tipranavir 
(RESIST) studies: An analysis of combined data from two randomised open-label trials. Lancet 2006;368:466-75.

99. Clotet B, Bellos N, Molina JM, et al. Efficacy and safety of darunavir-ritonavir at week 48 in treatment-experienced patients with HIV-1 infection in POWER 1 and 2: A pooled subgroup analysis of data from two randomised trials. Lancet 2007;369:1169-78.

100. Madruga JV, Cahn P, Grinsztejn B, et al. Efficacy and safety of TMC125 (etravirine) in treatment-experienced HIV-1-infected patients in DUET-1: 24-week results from a randomised, double-blind, placebo-controlled trial. Lancet 2007;370:29-38.

101. Lazzarin A, Campbell T, Clotet B, et al. Efficacy and safety of TMC125 (etravirine) in treatment-experienced HIV-1-infected patients in DUET-2: 24-week results from a randomised, double-blind, placebo-controlled trial. Lancet 2007;370:39-48.

102. Gulick RM, Lalezari J, Goodrich J, et al. Maraviroc for previously treated patients with R5 HIV-1 infection. N Engl J Med 2008;359:1429-41.

103. Steigbigel RT, Cooper DA, Kumar PN, et al. Raltegravir with optimized background therapy for resistant HIV-1 infection. N Engl J Med 2008;359:339-54.

104. Cooper DA, Steigbigel RT, Gatell JM, et al. Subgroup and resistance analyses of raltegravir for resistant HIV-1 infection. N Engl J Med 2008;359:355-65.

105. Steigbigel R, Cooper D, Eron J, et al. 96-week results from BENCHMRK 1 and 2, phase III studies of raltegravir in patients failing ART with triple-class-resistant HIV. 16th Conference on Retroviruses and Opportunistic Infections. Montreal, February 8 to 11,2009 . (Abst)

106. Lalezari JP, Henry K, O'Hearn M, et al. Enfuvirtide, an HIV-1 fusion inhibitor, for drug-resistant HIV infection in North and South America. N Engl J Med 2003;348:2175-85.

107. Lazzarin A, Clotet B, Cooper D, et al. Efficacy of enfuvirtide in patients infected with drug-resistant HIV-1 in Europe and Australia. N Engl J Med 2003;348:2186-95.

108. Lawrence J, Mayers DL, Hullsiek KH, et al. Structured treatment interruption in patients with multidrug-resistant human immunodeficiency virus. N Engl J Med 2003;349:837-46.

109. Walmsley S, Thorne A, Loutfy M, et al. A prospective randomized controlled trial of structured treatment interruption in HIV-infected patients failing highly active antiretroviral therapy (Canadian HIV Trials Network Study 164). J Acquir Immune Defic Syndr 2007;45:418-25.

110. Castagna A, Danise A, Menzo S, et al. Lamivudine monotherapy in HIV-1-infected patients harbouring a lamivudine-resistant virus: A randomized pilot study (E-184V study). AIDS 2006;20:795-803.

111. Campbell T, Smeaton L, De Grutolla V, et al. PEARLS (ACTG A5175): A multinational study of didanosine-EC, emtricitabine and atazanavir vs. co-formulated zidovudine/lamivudine and efavirenz for initial treatment of HIV-1 infection. XVII International AIDS Conference. Mexico City, August 3 to 8, 2008. (Abst) 


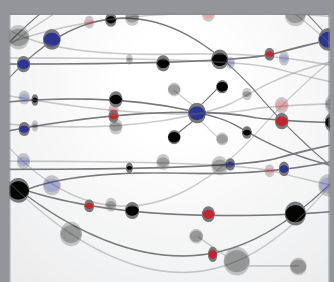

The Scientific World Journal
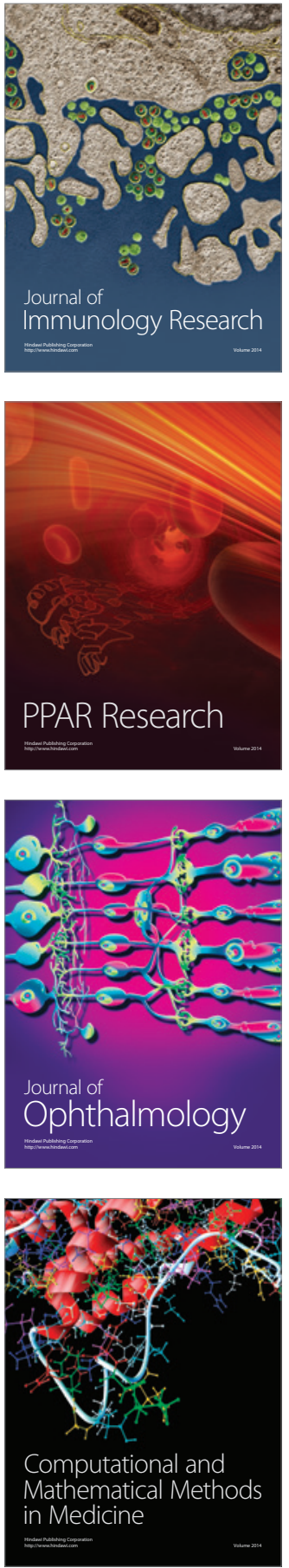

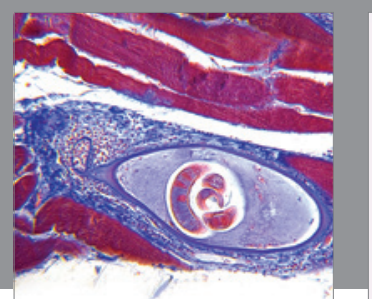

Gastroenterology Research and Practice

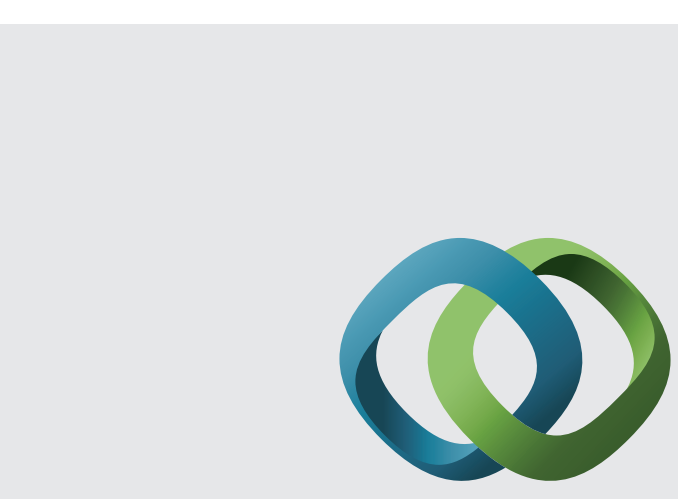

\section{Hindawi}

Submit your manuscripts at

http://www.hindawi.com
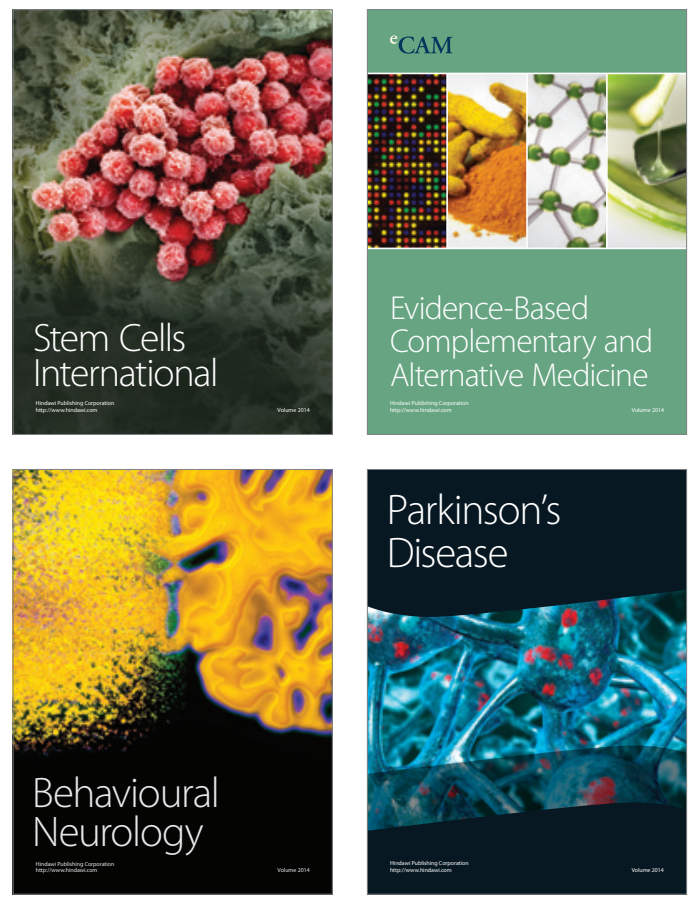
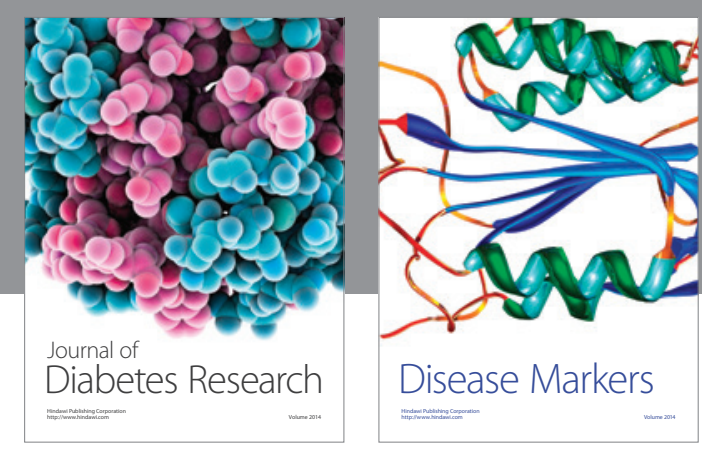

Disease Markers
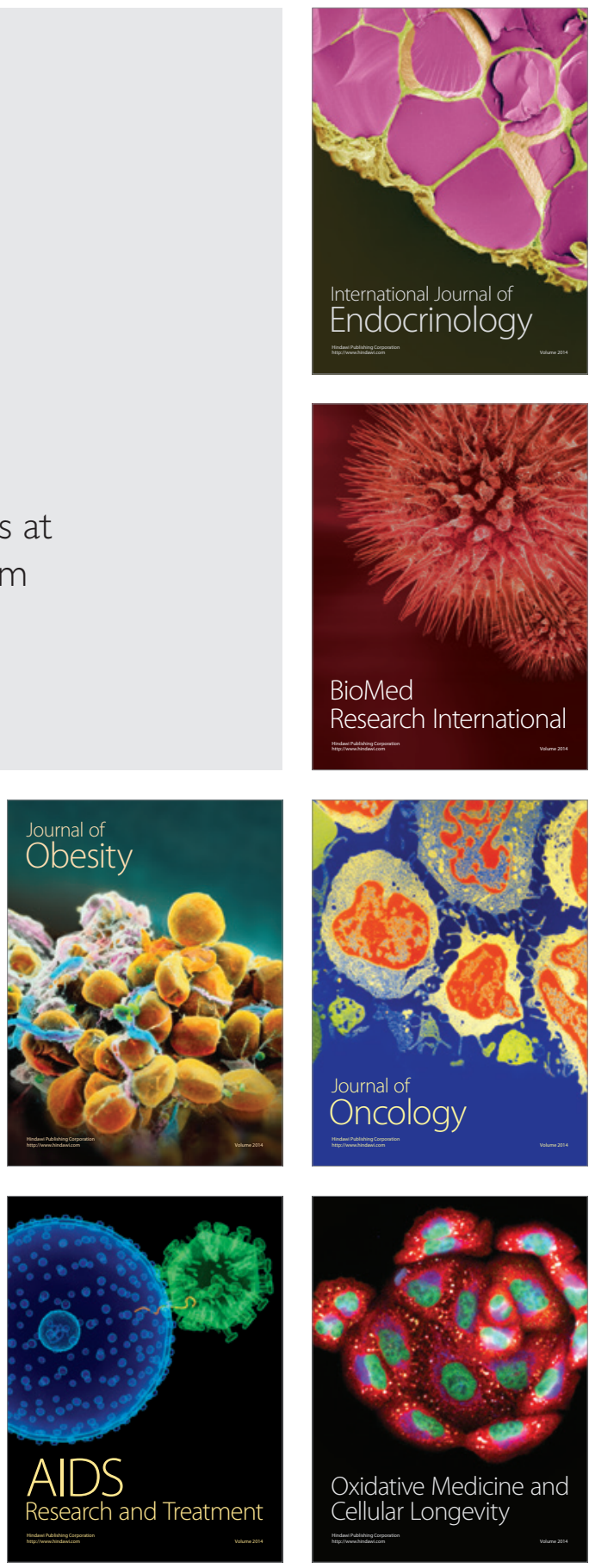